Communications in Physics, Vol. 26, No. 3 (2016), pp. 269-277

DOI:10.15625/0868-3166/26/3/8757

\title{
LIGHT ABSORPTION AND LUMINESCENCE PROPERTIES OF THE BLEND POLY(N-VINYLCARBAZOLE)/POLY(N-HEXYLTHIOPHENE)
}

\author{
NGUYEN PHUONG HOAI NAM ${ }^{1, \dagger}$, HOANG MAI HA ${ }^{2}$, NGO TRINH TUNG ${ }^{2}$, \\ DANG DINH LONG ${ }^{1}$, NGUYEN KHAC QUAN ${ }^{1}$, AND VU DUY LIEM ${ }^{1}$ \\ ${ }^{1}$ Faculty of Engineering Physics and Nanotechnology, \\ University of Engineering and Technology, Vietnam National University, Hanoi \\ 144 Xuan Thuy Road, Cau Giay District, Hanoi, Vietnam \\ ${ }^{2}$ Institute of Chemistry, Vietnam Academy of Science and Technology, \\ 18 Hoang Quoc Viet Road, Cau Giay District, Hanoi, Vietnam \\ ${ }^{\dagger} E$-mail: namnph@vnu.edu.vn \\ Received 04 October 2016
}

Accepted for publication 29 November 2016

\begin{abstract}
We have investigated the enhancement of light absorption and luminescence properties of the blend conducting polymers using poly( $N$-vinylcarbazole) and poly( $N$-hexylthiophene). The optimizedmaterial showed a broad absorption in the region from ultra violet to near infra-red and the better of luminescence ability than the pristine conducting polymers. The remarkable improvements in photoluminescence of the blends provide useful information to the application of this material in fabrication of optical - electronic devices.
\end{abstract}

Keywords: PVK, conducting polymer, blend polymer, light absorption, P3HT.

Classification numbers: 42.70.-a, 42.25.Bs, 78.55.Kz.

\section{INTRODUCTION}

Since the discovery of electroluminescence (EL) of organic molecules [1], rapid progress has been made in research on these materials due to their potential applications in flat panel display. Organic light-emitting diodes (OLEDs) have been applied to flat panel display due to its ease of manufacturing, all solid-state, a faster switching speed and a wider viewing angle, etc... Along with the developing of new technology, OLEDs have the potential to substitute liquid crystal display (LCDs) and to become the pacemaker in the display market. High performance organic light emitting diodes should have a low operating voltage, high efficiency and relatively good stability.

(C)2016 Vietnam Academy of Science and Technology 
In order to improve the efficiency of devices, various techniques are available as anode or cathode modification, annealing and optical coupling [1-4]. Application of conducting polymers to optoelectronic devices, such as light emitting diodes, and solar cells are of practical significance, because the polymer mixture can be easily prepared and modified by rich chemical procedures to meet optical and electronic requirements. Due to its electro- and photo-properties, poly(vinylcarbazole) (PVK), has been used in various technological applications [5,6]. Polymers based on this compound have been used to enhance LED emission and also for color tuning. In a study of EL of dye doped PVK systems [7,8], the hole transport properties of this polymer were demonstrated. Devices in which the emitting layer was formed by PVK blended with other polymeric systems have shown remarkable increases in luminescence efficiency, compared to those in which PVK was not incorporated. As examples one can cite blends of PVK as a matrix for a blue emitting copolyester containing isolated 1,2-dinaphthylene units [9], for poly(3-octyl thiophene) [10,11], and for PPV derivative with silane spacers [12], among others [13]. Other important reasons for the employment of PVK as a host are its favorable film-forming properties, durability at higher temperatures and hole mobility around $10^{-5} \mathrm{~cm}^{2} / \mathrm{Vs}$. In a recent communication we have also discussed the investigation of energy transfer from PVK - based with [2-methoxy-5-(2'-ethylhexyloxy)-1,4-phenylene vinylene] (MEH-PPV) [14]. In this study, the blend conducting polymers of PVK and poly(3-hexylthiophene) (P3HT) was fabricated. The blend PVK:P3HT enhances light absorption and improves photoluminescence. The incorporation of $\mathrm{TiO}_{2}$ nanocrystals with the blend polymer to make a nanocomposite such as PVK:P3HT:TiO ${ }_{2}$ aimed to improve the exciton formation in the components. Some kinds of organic light emitting diode (OLED) have been fabricated which using the blend PVK:P3HT and the blend nanocomposite PVK:P3HT:TiO ${ }_{2}$ as active layer, respectively. The current density - voltage (J-V) characteristics of the devices were also studied.

\section{EXPERIMENTAL}

The commercially available starting materials and solvents such as PVK, P3HT, chlorobenzene were purchased from Aldrich Chemical Co. and used without further purification. $\mathrm{TiO}_{2}$ anatase nanoparticles (Sigma - Aldrich) with average diameters of $20 \mathrm{~nm}$ were chosen for this study. Prior to deposition, the substrates were successively cleaned by using mixture of acetone and alcohol, alcohol and de-ionized water in an ultrasonic bath [1]. The thin films of pristine polymers and blend polymers PVK:P3HT with the difference ratios of weight fraction were obtained by mixing the components in chlorobenzene solvent. The solution at concentration of 13,75 $\mathrm{mg} / \mathrm{ml}$ was spin-coated onto the substrates and dried in vacuum $\left(\sim 10^{-3} \mathrm{mbar}\right)$ at $120^{\circ} \mathrm{C}$ for 60 minutes. The thickness of the films was controlled both by spin speed and by the concentration of the solution. The film thicknesses were measured by using a $\alpha$ step DEKTAK and found to be around $120 \mathrm{~nm}$. The surface morphology of the films were observed using "Hitachi" Field Emission Scanning Electron Microscopy (FE-SEM) S-4800. UV-visible absorption spectra of the films were recorded with UV-Vis SP3000-Nano spectrometer. The photoluminescence (PL) spectra were carried-out by using a FluoroMax -4 spectrophotometer. All the photo physical measurements were performed at room temperature in air.

Indium-tin-oxide (ITO) and aluminium (Al) were used as an anode and a cathode, respectively. ITO glass substrates with a measured sheet resistance of $15 \Omega /$ square (Merck) was 
used after ultrasonically cleaning in a series of organic solvents (ethanol, methanol, and acetone). The thin films of poly (3,4-ethylenedioxythiophene):poly(styrenesulfonate) (PEDOT-PSS) were spin-casted onto the ITO substrate at $300 \mathrm{rpm}$ for $10 \mathrm{~s}$ and at $3000 \mathrm{rpm}$ for $60 \mathrm{~s}$, consecutively. The structure of the organic light emitting diode (OLED) which using the blend PVK:P3HT and the blend nanocomposite PVK:P3HT: $\mathrm{TiO}_{2}$ as active layer, respectively, were the following: ITO/PEDOT-PSS/PVK:P3HT/Al and ITO/PEDOT-PSS/ PVK:P3HT:TiO $2 / A 1$. The Al cathodes $(100 \mathrm{~nm})$ were thermally evaporated through shadow mask defining an active area of $0.04 \mathrm{~cm}^{2}$. The current-voltage $(J-V)$ characteristics of the devices were measured on an Auto-Lab Potentiostat PGS-30

\section{RESULTS AND DISCUSSION}

Fig. 1 shows the FE-SEM image of the blend film PVK:P3HT (Fig. 1a) and the blend nanocomposite PVK:P3HT: $\mathrm{TiO}_{2}$ films with embedding of $50 \mathrm{wt} \% \mathrm{TiO}_{2}$ nanocrystals (Fig. $1 \mathrm{~b}$ ).

(a)

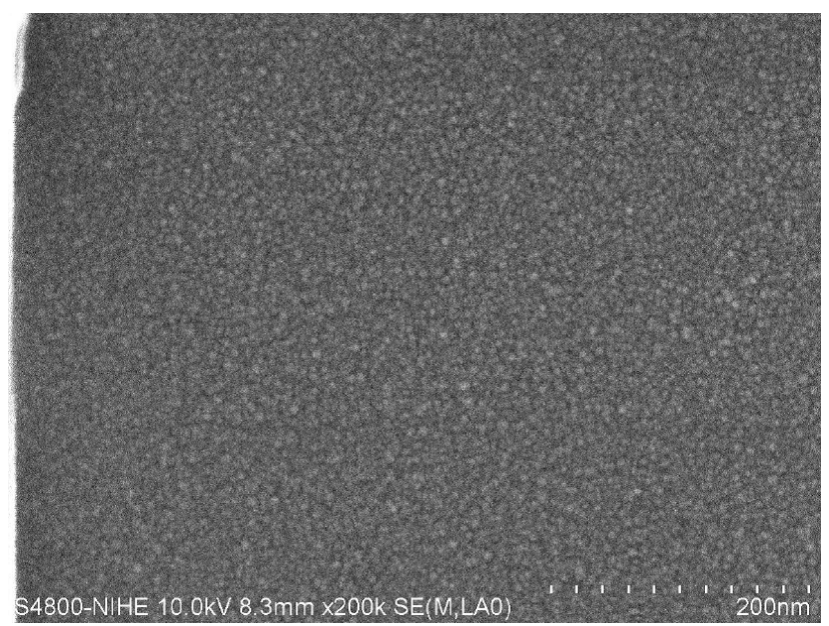

(b)

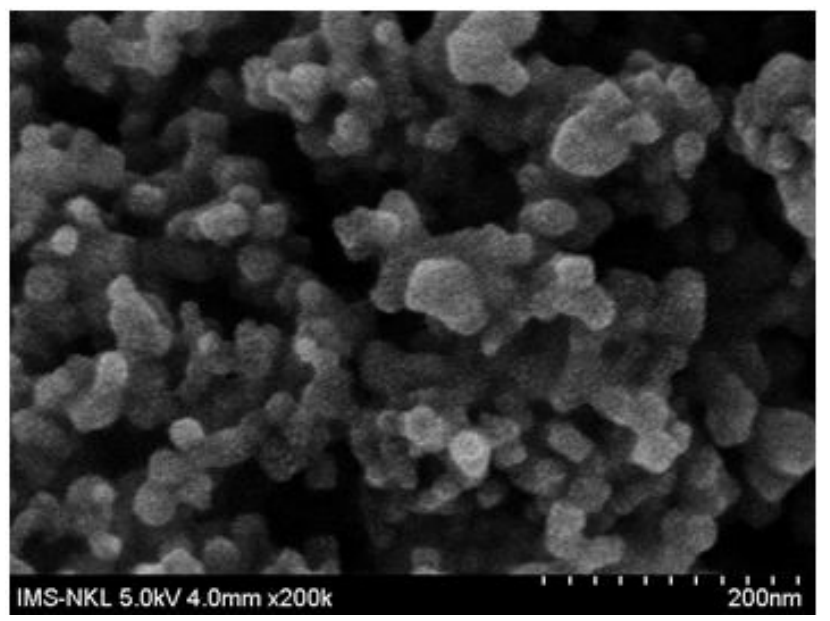

Fig. 1. FESEM of the surface of PVK:P3HT (a) and PVK:P3HT:TiO 2 (b) thin films. 
Figure 1a shows that the distribution of PVK and P3HT is perfect and the blend polymers thin film is unifrom. The $20 \mathrm{~nm}$ diameter $\mathrm{TiO}_{2}$ nanocrystals are shown in Fig. $1 \mathrm{~b}$ and the distribution of $\mathrm{TiO}_{2}$ in polymer matrix is good as well as showing the long backbone of the polymer moleculars.

Figure 2 compares the UV-vis spectra of pristine PVK, P3HT (Fig. 2a) and the blend PVK:P3HT with the difference ratios of weight fraction (Fig. 2b).

(a)

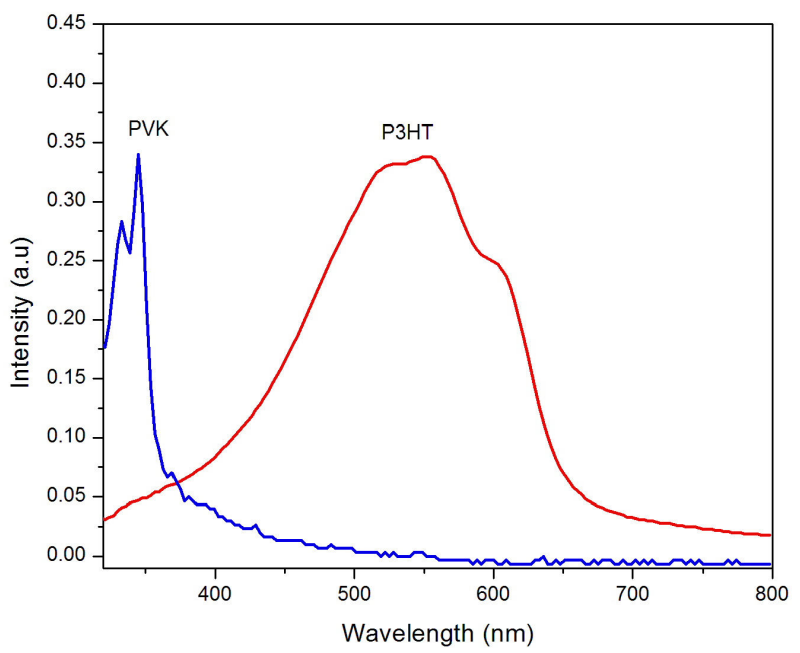

(b)

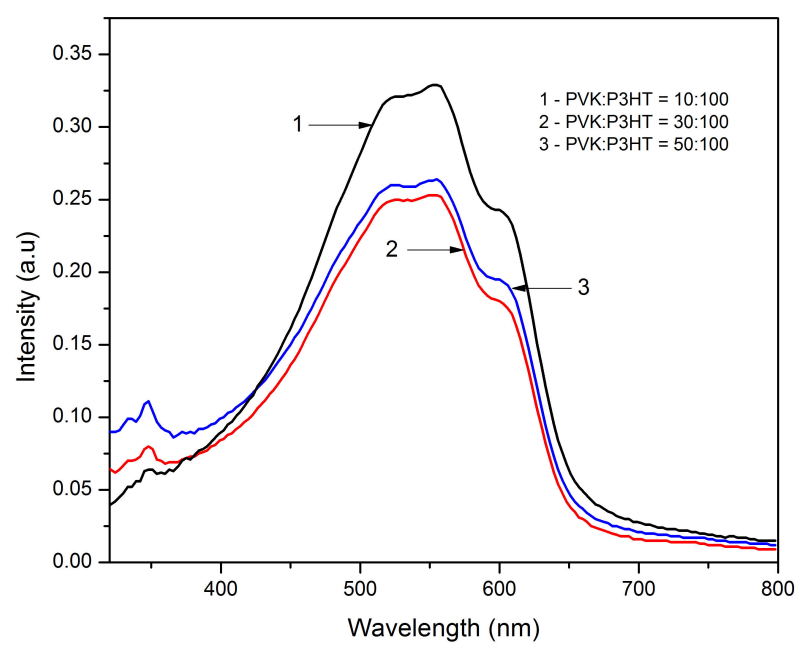

Fig. 2. UV-Vis absorption spectra of (a) pristine polymers and (b) blend polymers.

Figure 2a shows the PVK absorption is in the ultra violet wavelength and maximum absorption at $345 \mathrm{~nm}$ due to the transition $\pi-\pi^{*}$ of carbazole groups [13]. P3HT reveals an absorption in the region of 400 to $670 \mathrm{~nm}$ with a maximum absorption at $553 \mathrm{~nm}$. The blend PVK:P3HT shows the absorption in the ultra violet band with maximum at $345 \mathrm{~nm}$ and a broad absorption ranged 
from 400 to $670 \mathrm{~nm}$ with maximum at $553 \mathrm{~nm}$ corresponding to PVK and P3HT, respectively. It means that there was no chemical interaction between PVK and P3HT moleculars. When the content of PVK in the blend increases the UV light absorption intensity of the blend increases and the visible light absorption decreases. At the ratio $P V K: P 3 H T=1: 2$ (weight fraction), the blend shows the good absoption intensity in UV as well in visible light. This result can be explained that at the optimal ratio the internal interaction between PVK and P3HT moleculars caused the best of the distribution of the polymers in the blend. The light absorption of the blend film is obviously increased. In addition, the blend polymers with the ratio PVK:P3HT equal to 1:2 has advantages over pristine polymers such as P3HT due to its ultra violet light absorption and thermal stability. This material is quite promising for its application in optoelectronic devices.

The effect of $\mathrm{TiO}_{2}$ nanocrystals on the light absorption of the blend nanocomposite PVK:P3HT:TiO 2 is shown in Fig. 3.

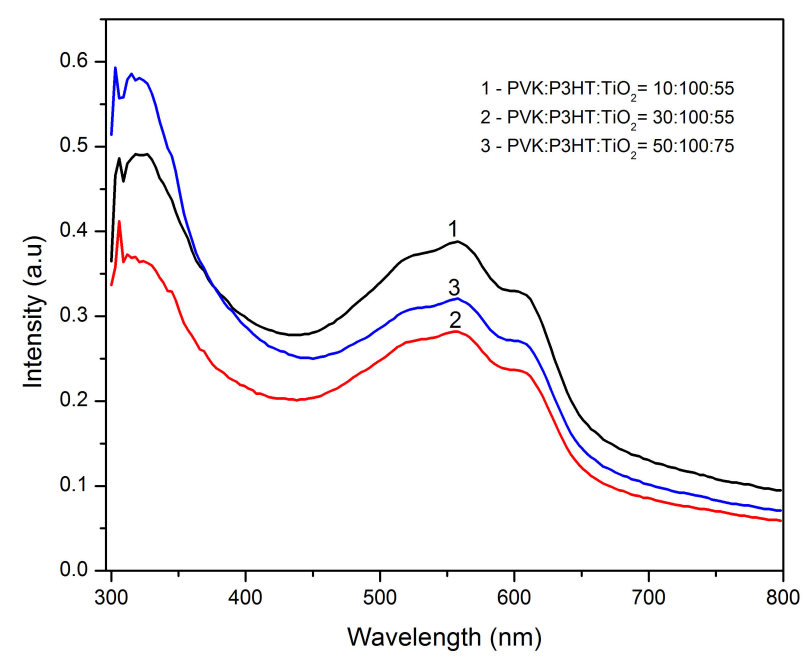

Fig. 3. UV-Vis absorption spectra of the PVK:P3HT:TiO ${ }_{2}$ thin films.

The UV light absorption of the blend nanocomposite films have been increasesed significantly by the incorporation of $\mathrm{TiO}_{2}$ nanocrystals in the blend polymers films due to the ability to absorb UV light of the $\mathrm{TiO}_{2}$.

Figure 4 shows the photoluminescence spectra of the pristine polymers and the blend polymers films.

It can be seen that the blend polymers films emit purple light when excited at $325 \mathrm{~nm}$ and red-organe light when excited at $530 \mathrm{~nm}$, respectively. A plausible explanation for the red shipt of the photoluminescence spectra when increasing the content of PVK in the blend is the interaction between the PVK and P3HT moleculars. With the optimal ratio the blend film shows the higher luminescence intensity than that of the pristine polymers.

The photoluminescence spectra of the blend nanocomposite films excited at $325 \mathrm{~nm}$ and $530 \mathrm{~nm}$ are shown in Fig. 5.

Fig. 5 shows that the luminescence intensity of the blend nanocomposite PVK:P3HT: $\mathrm{TiO}_{2}$ film much higher than that of the pristine polymers as well as the blend polymers 
(a)

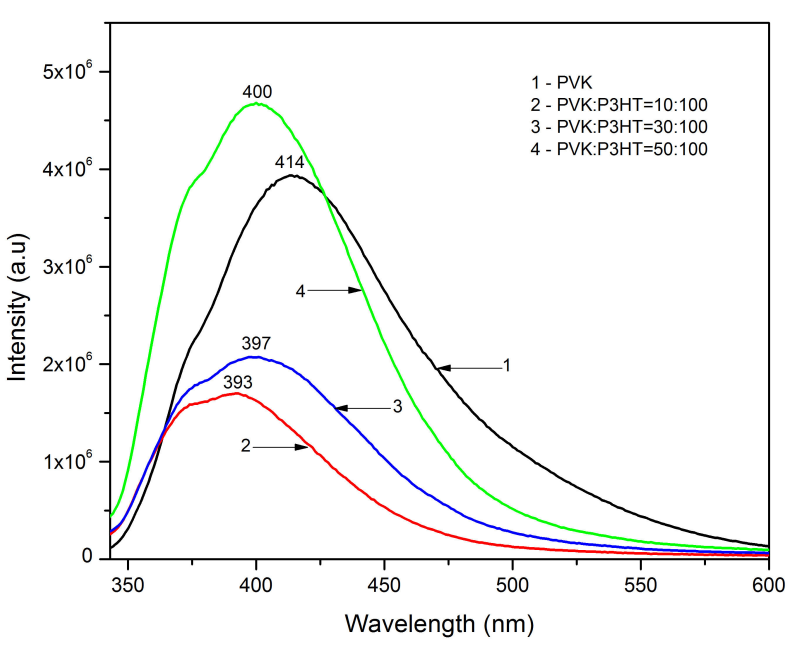

(b)

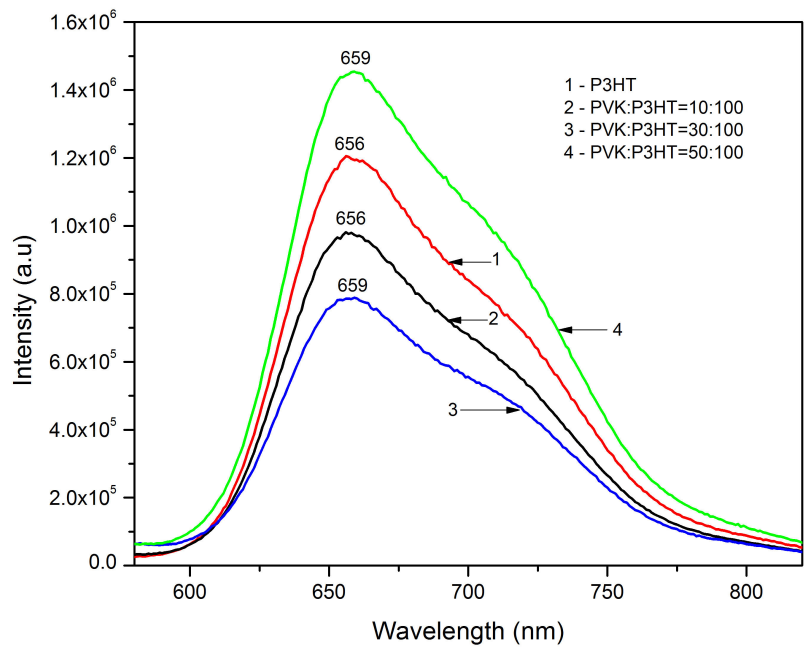

Fig. 4. Photoluminescence spectra of the pristine polymers and the blend polymers films, excited at short wavelength $325 \mathrm{~nm}$ (a) and long wavelength $530 \mathrm{~nm}$ (b).

films. This is probably due to the interface area of the nanocomposite film much larger than that of the blend film as we can see in Fig. 1.

The OLED which using the blend polymers with the ratio PVK:P3HT $=1: 2$ and the blend nanocopmposite films as active layers were fabricated and the structure of the devices were ITO/PEDOT-PSS/PVK:P3HT/Al and ITO/PEDOT-PSS/PVK:P3HT:TiO $2 / \mathrm{Al}$, respectively. The thin films of poly (3,4-ethylenedioxythiophene):poly(styrenesulfonate) (PEDOT:PSS) were spincasted onto the ITO substrate at $300 \mathrm{rpm}$ for $10 \mathrm{~s}$ and at $3000 \mathrm{rpm}$ for $60 \mathrm{~s}$, consecutively. Fig. 6 shows the density - voltage (J-V) characteristics of these devices.

Fig. 6 presents that the $J-V$ performances of the devices are strongly dependent on the presence of the blend nanocomposite thin film PVK:P3HT:TiO 2 . It can be seen that the current 
(a)

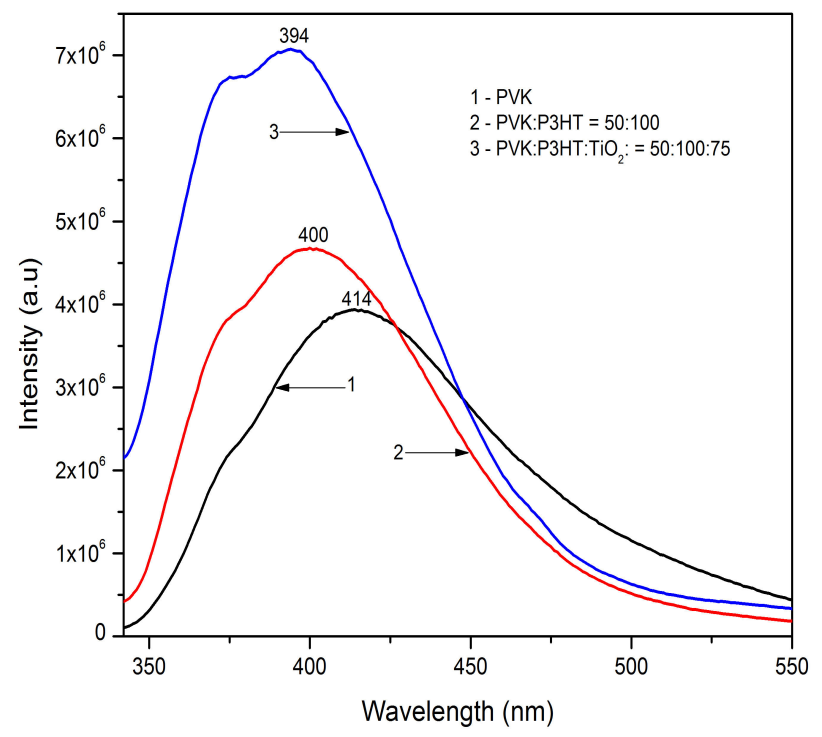

(b)

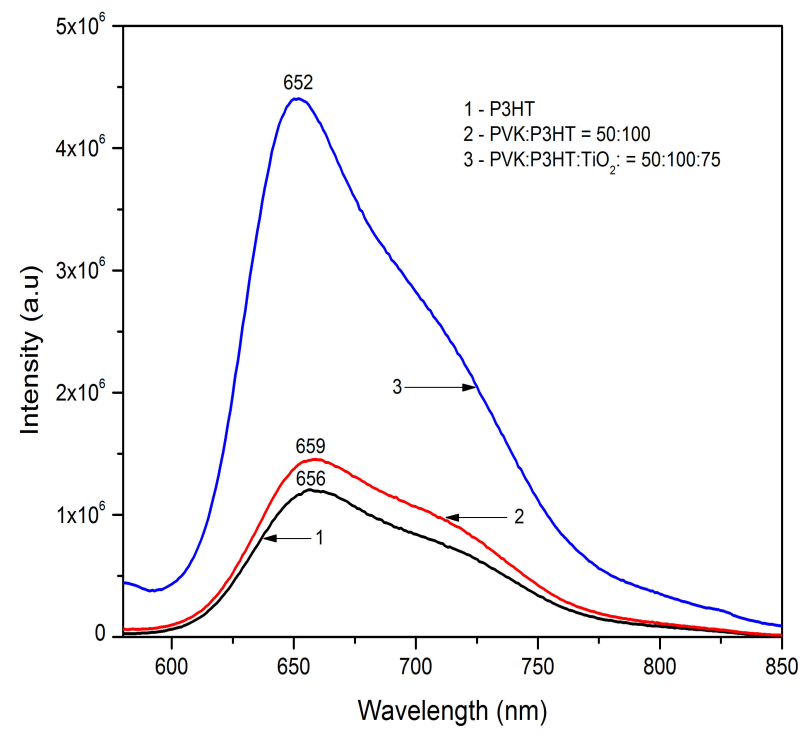

Fig. 5. Photoluminescence spectra of pristine polymers and nanocomposite films, excited at short wavelength $325 \mathrm{~nm}$ (a) and long wavelength $530 \mathrm{~nm}$ (b).

density of the device ITO/PEDOT-PSS/PVK:P3HT:TiO $2 / \mathrm{Al}$ are much higher compared with those of the device ITO/PEDOT-PSS/PVK:P3HT/Al at the same operating voltage. Also, the threshold field of the device ITO/PEDOT-PSS/PVK:P3HT:TiO $2 / \mathrm{Al}$ was decreased to lower than $2.5 \mathrm{~V}$. The high performance of the devices due to the ability to absorb light of the bend polymers and the improvements of the performance of the device which using the blend nanocomposite can be considered in order to explain the behavior of the $\mathrm{TiO}_{2}$ nanoparticle - modified the blend conducting polymers. 


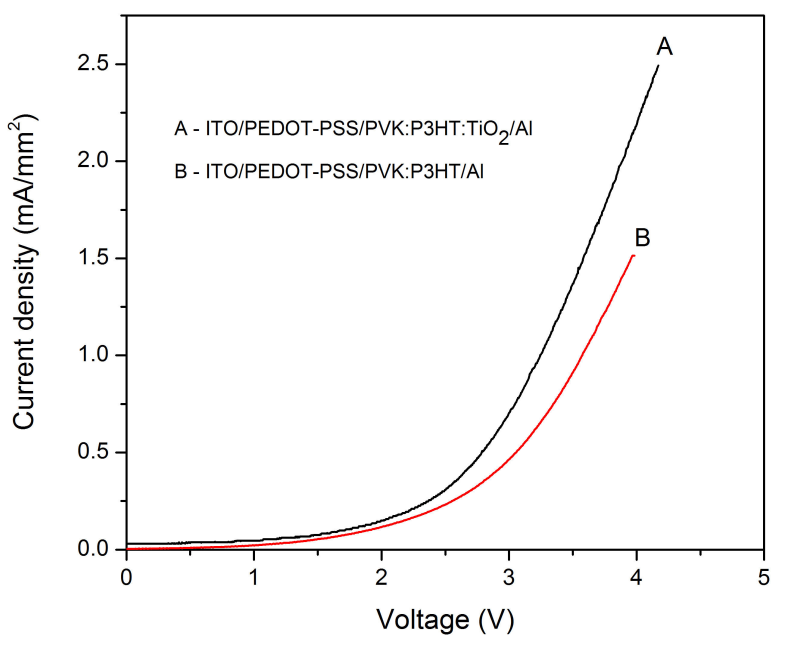

Fig. 6. The J-V characteristics of the devices.

\section{CONCLUSION}

We have fabricated and investigated the enhancement of light absorption and luminescence properties of the blend conducting polymers using poly $(\mathrm{N}$-vinylcarbazole $)$ and poly $(\mathrm{N}$ hexylthiophene). The optimized material showed a broad absorption in the region from ultra violet to near infra-red and the better of luminescence ability than the pristine conducting polymers. The remarkable improvements in photoluminescence of the blends nanocomposite material PVK:P3HT:TiO 2 provide useful information to the application of this material in fabrication of optical - electronic devices. The better of the performance of the device can be explained by the modified blend conducting polymers with nanoparticle $\mathrm{TiO}_{2}$.

\section{ACKNOWLEDGMENTS}

This work has been supported by Vietnam National University, Hanoi (VNU), under Project No. QG.15.26.

\section{REFERENCES}

[1] C. W. Tang and S. A. Van Slyke, Appl. Phys. Lett. 51 (1987) 913.

[2] J. H. Burroughes, D. D. C Bradley, A. R. Brown, R. N. Marks, K. Mackay, R. H. Friend, P. L. Burns and A. B. Holmes, Nature 347 (1990) 608.

[3] J. Kido, K. Hongawa, K. Okuyama and K. Nagai, Appl. Phys. Lett. 64 (1994) 815.

[4] A. R. Brown, N. C. Greenham, J. H. Burroughes, D. D. C. Bradley, R. H. Friend, P. L. Burn, A. Kraft and Holmes A. B. Holmes, Chem. Phys. Lett. 200 (1992) 46.

[5] R. F. Cossielo, A. Cirpan, F. E. Karasz, L. C. Akcelrud and T. D. Z. Atvars, Synth. Met. 158 (2008) 219.

[6] J. Gruber, R. W. C. Li, L. H. J. M. C. Aguiar, T. L. Garcia, H. P. M. Oliveira and T. D. Z. Atvars, Synth. Met. 156 (2006) 104.

[7] L. Akcelrud, Prog. Polym. Sci. 28 (2003) 875.

[8] J. R. Tozoni, F. E. G. Guimara es, T. D. Z. Atvars, B. Nowacki, L. Akcelrud and T. J. Bonagamba, Eur. Polym. J. 45 (2009) 2467. 
[9] J. W. Yu, J. K. Kim, D. Y. Kim, C. Kim, N. W. Song and D. Kim, Curr. Appl. Phys. 6 (2006) 59.

[10] T. W. Lee, J. H. Park, O. O. Park, J. Lee and J. C. Kim, Opt. Mater. 30 (2007) 486.

[11] L. Mort and G. Pfister, Electronic properties of polymers, New York: Wiley/Interscience, 1982.

[12] L. O. Palsson, H. L. Vaughan, A. P. Monkman, J. Chem. Phys. 125 (2006) 164701.

[13] N. P. H. Nam, S. W. Cha, B. S. Kim, S.-H. Choi, D. S. Choi, J.-I. Jin, Synth. Met. 130 (2002) 271.

[14] N.N. Dinh, N.P.H. Nam and D.N. Chung, Comm. Phys. 21 (2011) 4. 